\title{
Upward Flame Spread Along a Vertical Solid for Transient Local Heat Release Rate
}

\author{
Y. HASEMI and M. YOSHIDA
}

Building Research Institute

Tatehara 1, Tsukuba-City, Ibaraki, 305, Japan

\section{N. YASUI}

Science University of Tokyo, School of Science and Engineering

Yamazaki, Noda-City, Chiba, 278, Japan

\section{W. J. PARKER}

Building and Fire Research Laboratory, National Institute of Standards and Technology Gaithersburg, Md., 20899, U.S.A.

\section{ABSTRACT}

Theoretical and experimental analysis of turbulent upward flame spread along a vertical solid is presented. A conventional flame spread model based on a linearized flame height approximation is generalized to incorporate burnout effects. The model is verified against full-scale flame spread tests using material heat release data obtained from intermediate-scale tests in which the time history of surface heat flux during the flame spread tests was reproduced.

Key Words : upward flame spread, heat release, burnout, charring material.

\section{TERMINOLOGY}

$\mathrm{C}_{\mathrm{p}}$ :specific heat of air, $\mathrm{K}$ :constant $\left\{\left(\mathrm{x}_{\mathrm{f}}-\mathrm{x}_{\mathrm{b}}\right) / \mathrm{Q}_{\ell}\right\}, \mathrm{Q}_{0}$ :heat release rate per unit width due to ignition source, $Q_{\ell}$ : heat release rate per unit width, $Q_{\ell} *: Q_{\ell} / \rho_{o} C_{p} T_{o} g^{1 / 2}\left(x_{p}-x_{b}\right)^{3 / 2}, T_{i g}$ : ignition temperature, $\mathrm{T}_{\mathrm{o}}$ :ambient temperature, $\mathrm{T}_{\mathrm{si}}$ : initial surface temperature, $\mathrm{V}_{\mathrm{p}}$ :flame spreading velocity, a:constant $\left(\mathrm{Kq}_{\mathrm{o}}\right)$, g:gravitational acceleration, $\mathrm{k} \rho$ c:thermal inertia, $\mathrm{q}(\mathrm{t})$ : local heat release rate per unit area, $q_{n}$ :peak $q(t)$ value, $t$ :time, $t^{*}$ :time between the arrivals of flame front and of pyrolysis front, $t_{\mathrm{b}}$ :bumout time, $\mathrm{x}_{\mathrm{b}}$ :burnout front height, $\mathrm{x}_{\mathrm{f}}$ :flame front height, $\mathrm{x}_{\mathrm{p}}$ : pyrolysis front height, $x_{\mathrm{po}}$ :pilot flame height, $\mathrm{x}_{\mathrm{poff}}$ :maximum pyrolysis front height, $\lambda$ : constant, $\rho_{\mathrm{o}}$ :density of ambient air, $\tau$ :characteristic flame spread time, $\Psi: \pi \mathrm{k} \rho \mathrm{c}\left(\mathrm{T}_{\mathrm{ig}}-\mathrm{T}_{\mathrm{o}}\right)^{2}$ $\mathrm{V}_{\mathrm{p}} / \mathrm{x}_{\mathrm{p}}$. A Symbol in italics is the Laplace transform of the variable represented by that symbol. 


\section{INTRODUCTION}

Modeling of upward flame spread along a vertical combustible solid showing transient local pyrolysis is an important subject, since the process is not yet enough understood in spite of its importance for the growth of fire and it is widely recognized that local pyrolysis during a fire is commonly transient. Among several approaches to model this complicated process $[1] \sim[8]$, an analytical formulation based on the linearized flame height approximation, SQW equation[1], gives a simple framework to evaluate overall characteristics of flame spread from material fire properties. Analytical solutions of SQW equation have been obtained for typical material heat release characteristics, and a diagram to predict asymptotic flame spread behavior has been proposed[4,7]. However, the model still has some theoretical difficulty in the treatment of the effects of burnout, and is not yet verified quantitatively against actual upward flame spread measurements. This paper intends to make refinement of the model and show comparison of the theory with full-scale fire tests.

\section{GENERALIZED SQW EQUATION}

A Volterra type integral equation has been derived for upward flame spread velocity assuming proportionality of $\mathrm{V}_{\mathrm{p}}$ to the distance between the flame front and the pyrolysis front[1]. In this formulation, location of the flame front is assumed to be proportional to the total heat release rate due to the ignition source and the pyrolysis from the wall surface. Also, the ignition source is assumed to contribute fuel to the wall flame continuously unless the ignition source is turned off when the wall surface is ignited. These assumptions are believed to be realistic as long as the wall flame does not disappear at any part of the wall surface once that part has been reached by the pyrolysis front. However, these assumptions will fail once local burnout is considered. Considering the burnout front in formulating the location of flame front and neglecting the contribution of fuel by the ignition source to the flame after the burnout front has become higher than the height of ignition flame, SQW equation is modified as

$$
\begin{aligned}
& \mathrm{V}_{\mathrm{p}}(\mathrm{t})=\left(\mathrm{x}_{\mathrm{f}}-\mathrm{x}_{\mathrm{p}}\right) / \tau=\left(\mathrm{KQ} \mathrm{Q}_{\ell}+\mathrm{x}_{\mathrm{b}}-\mathrm{x}_{\mathrm{p}}\right) / \tau=\left[\mathrm { K } \left[\mathrm{Q}_{\mathrm{o}}(\mathrm{t})\left\{\mathrm{U}(\mathrm{t})-\mathrm{U}\left(\mathrm{t}-\mathrm{t}_{\mathrm{b}}\right)\right\}+\mathrm{x}_{\mathrm{po}} \mathrm{q}(\mathrm{t})+\int_{0} \mathrm{t}_{\mathrm{q}}(\mathrm{t}-\right.\right. \\
& \left.\left.\xi) \mathrm{V}_{\mathrm{p}}(\xi) \mathrm{d} \xi\right]+\left\{\int_{0}{ }^{\mathrm{t}-\mathrm{tb}} \mathrm{V}_{\mathrm{p}}(\xi) \mathrm{d} \xi+\mathrm{x}_{\mathrm{po}}\right\} \mathrm{U}\left(\mathrm{t}-\mathrm{t}_{\mathrm{b}}\right)-\left\{\mathrm{x}_{\mathrm{po}}+\int_{0} \mathrm{t}_{\mathrm{p}}(\xi) \mathrm{d} \xi\right\}\right] / \tau
\end{aligned}
$$

where $U(t)$ is Heaviside's unit function. Taking Laplace transform of equation(1), the image function of $V_{p}(t), V_{p}(s)$, can be summarized as:

$$
V_{p}(\mathrm{~s}) / \mathrm{x}_{\mathrm{po}}=\left[\left\{Q_{o}{ }^{\prime}(\mathrm{s})-1\right\}\left\{1-\exp \left(-\mathrm{t}_{\mathrm{o}} \mathrm{s}\right)\right\}+\mathrm{K} q(\mathrm{~s})\right] \mathrm{s} /\left[\mathrm{s} \tau-\mathrm{sK} q(\mathrm{~s})+\left\{1-\exp \left(-\mathrm{t}_{\mathrm{b}} \mathrm{s}\right)\right\}\right]
$$

where $Q_{o}{ }^{\prime}(\mathrm{s})$ is the Laplace transform of $\mathrm{Q}_{0}(\mathrm{t}) / \mathrm{x}_{\mathrm{po}}$. Representation of the right hand side of equation(2) only with $Q_{o}{ }^{\prime}(s), q(s), \tau$ and $\mathrm{t}_{\mathrm{b}}$ means that the solution of equation(1) for $\mathrm{v}_{\mathrm{p}}$, or $x_{p}$, divided by $x_{p o}$ become a function only of material heat release, $\tau$, and the mode of ignition source, as the $\lambda \tau-\mathrm{Kq}_{\mathrm{o}}$ plane has been divided into several domains according to the mathematical features of the solutions of equation(2), i.e. the acceleration/deceleration and the divergence/convergence of flame spread for various $q(t)$ functional forms, without the burnout 
terms(Baroudi-Kokkala diagram,[7]). It is obvious that, in an actual fire, significant fire spread occur in the domain where divergence of the solution is expected mathematically. However, it is not yet clear what happens under the condition where only the convergence is expected especially in a room with a combustible ceiling, since once $x_{p}$ becomes greater than the ceiling height the wall fire may ignite the ceiling or at least cause flame extension over the ceiling surface, which is recognized as a typical cause of ignition of combustibles on the floor. Location of the maximum pyrolysis front, $\mathrm{x}_{\text {poff }}$, can be a measure to see how high upward flame spread may approach, and is obtained by calculating $x_{p}$ at which $v_{p}=0$ is achieved. From the above discussions, $x_{\text {poff }} / x_{p o}$ should be a constant for a given material and heating condition. If local heat release is represented by an exponential decay function, $q(t)=q_{o} \exp (-\lambda t)$, and local burnout is ignored, $x_{\text {pof }} / x_{p o}$ can then be calculated by substituting the time when $v_{p}=0$ is achieved, $t_{\text {off }}$, into $t$ in the analytical solution of SQW equation as:

\section{a) Sustained Pilot Flame}

$x_{p}(t) / x_{p o}=1+a\left\{\exp \left(s_{1} t\right)-\exp \left(s_{2} t\right)\right\} / \tau\left(s_{1}-s_{2}\right)$

$\mathrm{t}_{\mathrm{off}}=\ln \left(\mathrm{s}_{1} / \mathrm{s}_{2}\right) /\left(\mathrm{s}_{1}-\mathrm{s}_{2}\right)$

b)Pilot Flame Off After Ignition On the Wall Surface

$\mathrm{x}_{\mathrm{p}}(\mathrm{t}) / \mathrm{x}_{\mathrm{po}}=1+(\mathrm{a}-1)\left[\left\{1-\lambda / \mathrm{s}_{1}(\mathrm{a}-1)\right\} \exp \left(\mathrm{s}_{1} \mathrm{t}\right)-\left\{1-\lambda / \mathrm{s}_{2}(\mathrm{a}-1)\right\} \exp \left(\mathrm{s}_{2} \mathrm{t}\right)\right] / \tau\left(\mathrm{s}_{1}-\mathrm{s}_{2}\right)-\lambda / \tau \mathrm{s}_{1} \mathrm{~s}_{2}$

$\mathrm{t}_{\mathrm{off}}=\ln \left[\left\{\mathrm{s}_{2}(\mathrm{a}-1)-\lambda\right\} /\left\{\mathrm{s}_{1}(\mathrm{a}-1)-\lambda\right\}\right] /\left(\mathrm{s}_{1}-\mathrm{s}_{2}\right)$

where $s_{1}$ and $s_{2}$ are the residues of equation(2) with $q(s)=q_{o} /(s+\lambda)$ and $t_{\mathrm{b}} \rightarrow \infty \cdot x_{\text {poff }} / x_{\text {po }}$ thus becomes a function of $\lambda \tau$ and $a$, and the contours of $x_{\text {poff }} / x_{\text {po }}$ can be drawn on the BaroudiKokkala diagram(Figure 1(a),(b)). Although the criticality of the asymptotic behavior, i.e. $x_{\text {poff }} / x_{p_{0}} \rightarrow \infty$, is independent of the mode of ignition source, there is notable difference in $x_{\text {poff }} / x_{\text {po }}$ distribution between the two ignition-source conditions especially for $x_{\text {poff }} / x_{\text {po }}$ less than around 10. It is also noteworthy that the contours are dense near the $x_{\text {poff }} / x_{\text {po }} \rightarrow \infty$ limit; this suggests that flame spread is generally quite sensitive to material properties if $\lambda \tau$ and $\mathrm{Kq}_{0}$ fall into the vicinity of the $x_{\text {poff }} / x_{\text {po }} \rightarrow \infty$ limit. Repeatability and predictability of the phenomena are also believed to be poor in the large $x_{\text {poff }} / x_{\text {po }}$ domain. This low predictability is believed to be important for the fire safety evaluation.

Inverse Laplace transform of equation(2) is generally represented by an infinite series of the product of an exponential function and trigonometric functions[8]. Local heat release rate represented by a rectangular function, typical of a thin lining, is a representative situation in which consideration of the burnout is essential. Representing this heat release by $q(t)=q_{o}\{U(t)$ 


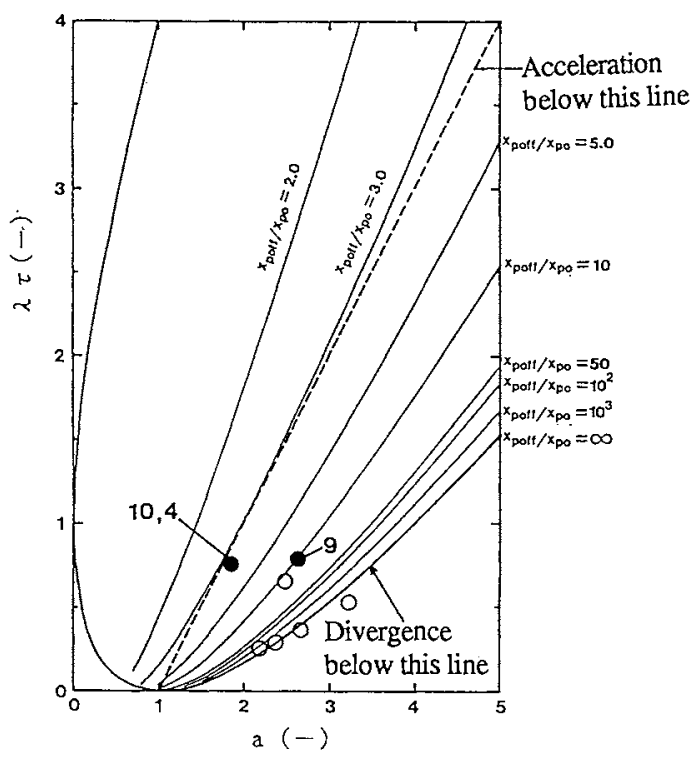

(a) Sustained Pilot Flame (dots in the figure are experimental and will be discussed in a later section of the paper)

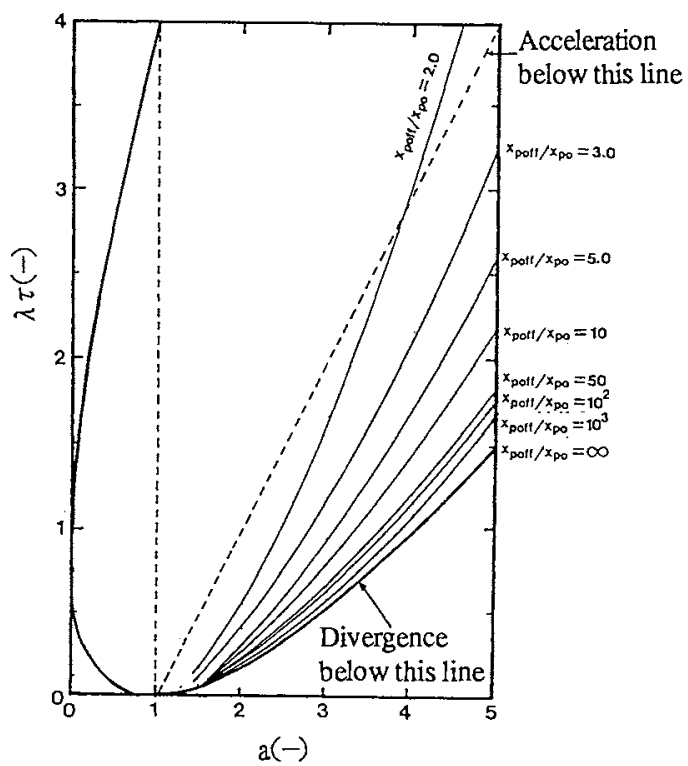

(b)Pilot Flame Off after Ignition on the Wall Surface

FIGURE 1 Criticality for Acceleration/Deceleration and Divergence/Convergence of Upward Flame Spread, and $x_{\text {poff }} f x_{p o}$ Contours for $q(t)=q_{o} \exp (-\lambda t)$ without Consideration of Burnout 


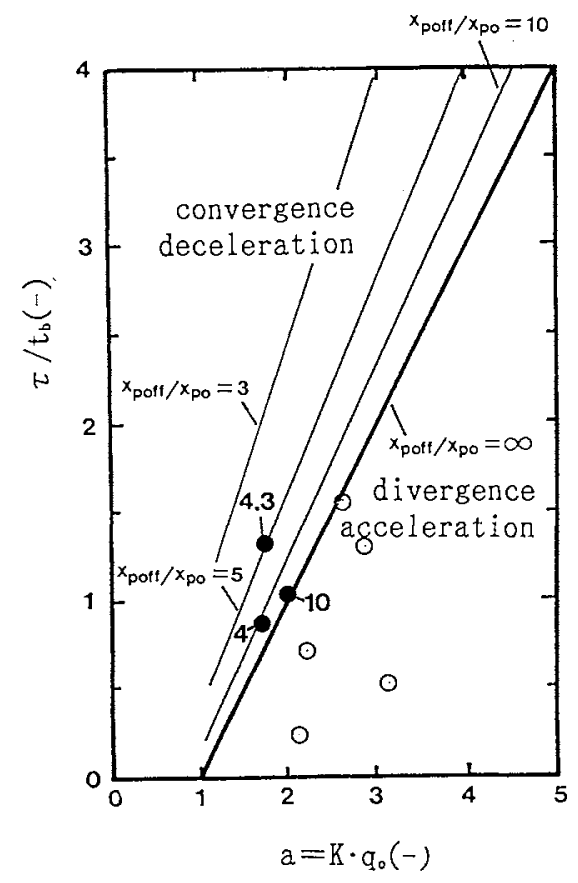

FIGURE 2 Criticality for Flame Spread Acceleration/Deceleration and $\mathbf{x}_{\text {poff }} / \mathbf{x}_{\text {po }}$ Contours for $q(t)=q_{0}\left\{U(t)-U\left(t-t_{b}\right)\right\}$, Sustained Pilot Flame

(dots in the figure are experimental and will be discussed in a later section)

$\left.-\mathrm{U}\left(\mathrm{t}-\mathrm{t}_{\mathrm{b}}\right)\right\}$, the denominator of equation(2) becomes

$$
\Lambda(s)=s \tau+(1-a)\left\{1-\exp \left(-t_{b} s\right)\right\}
$$

Since $\Lambda(s)=0$ has at least one real root other than the obvious real root $s=0, V_{p}(t)$ has always a term represented by an exponential function of time(without trigonometric functions), which is believed to dominate the asymptotic behavior[9]. Both the divergence/convergence and acceleration/deceleration can be judged only by the sign of this root, and the criticality for these two mathematical behaviors are given by $\tau / t_{b}=a-1$, whilst these two criticalities are not identical for $q(t)=q_{0} \exp (-\lambda t)$ [7]. For $\tau / t_{b}>a-1$, flame spread is decelerated from the beginning and $V_{p}$ converges gradually to zero, while, for $\tau / t_{b}<a-1$, flame spread is accelerated and lasts as far as the combustible wall continues. This is consistent with a simpler modelling of upward flame spread over a thin wall lining[6]. Figure 2 shows $x_{p o f f} / x_{p o}$ contours for a sustained ignition source on $a \tau / t_{b}$-a diagram.

\section{FLAME SPREAD TESTS}

Flame spread tests were conducted on charring building materials using a $0.9 \mathrm{~m}$ wide and $3.2 \mathrm{~m}$ 
tall propane-air radiant panel as the external radiation source. Size of the specimens was $2.4 \mathrm{~m}$ tall and $0.6 \sim 1.2 \mathrm{~m}$ wide. The specimen was ignited using solid alcohol or a line burner as wide
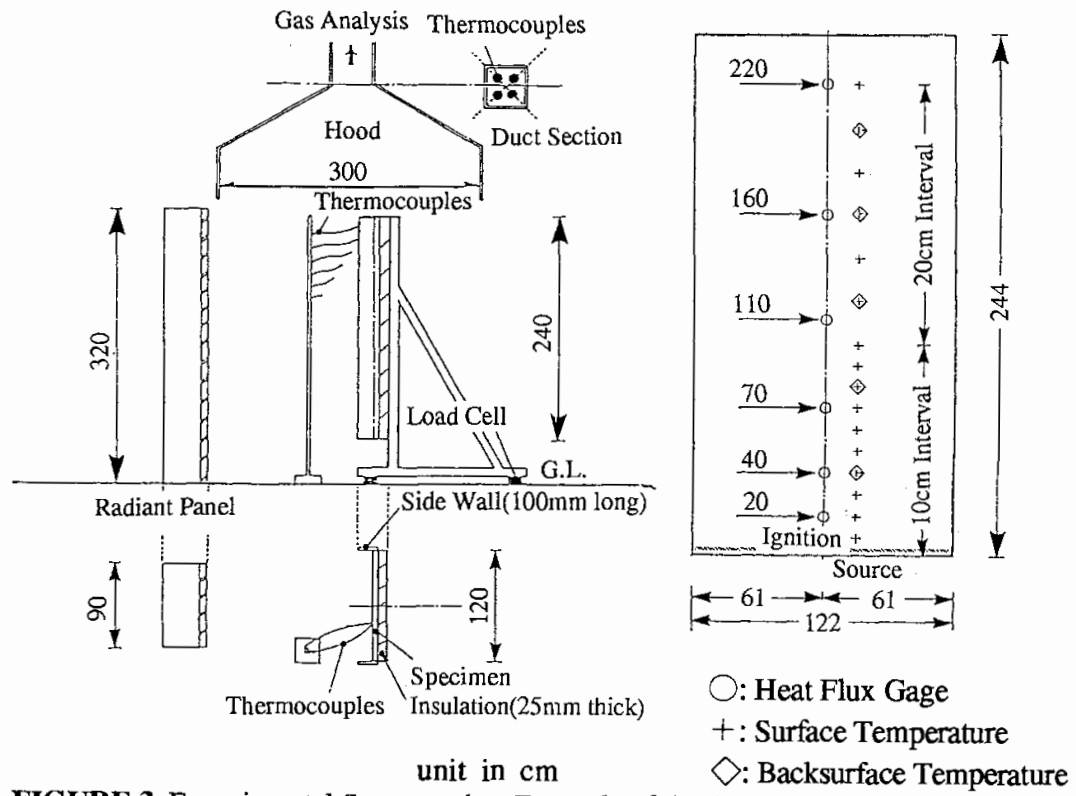

FIGURE 3 Experimental Set-up and an Example of the Arrangment of Test Specimen

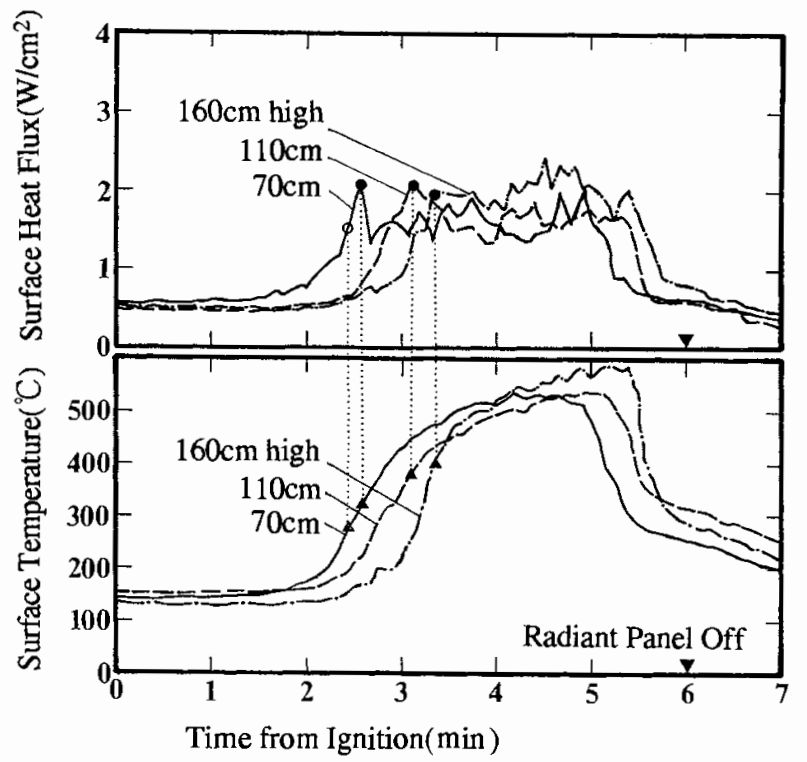

Figure 4 Time History of Surface Temperature and Heat Flux during a Flame Spread Test,12.6mm thick Douglas Fir Particleboard, $q_{\mathrm{e}}=6.0 \mathrm{~kW} / \mathrm{m}^{2}$, $\mathrm{T}_{\mathrm{si}}=149^{\circ} \mathrm{C}, \bigcirc$ :color change) 


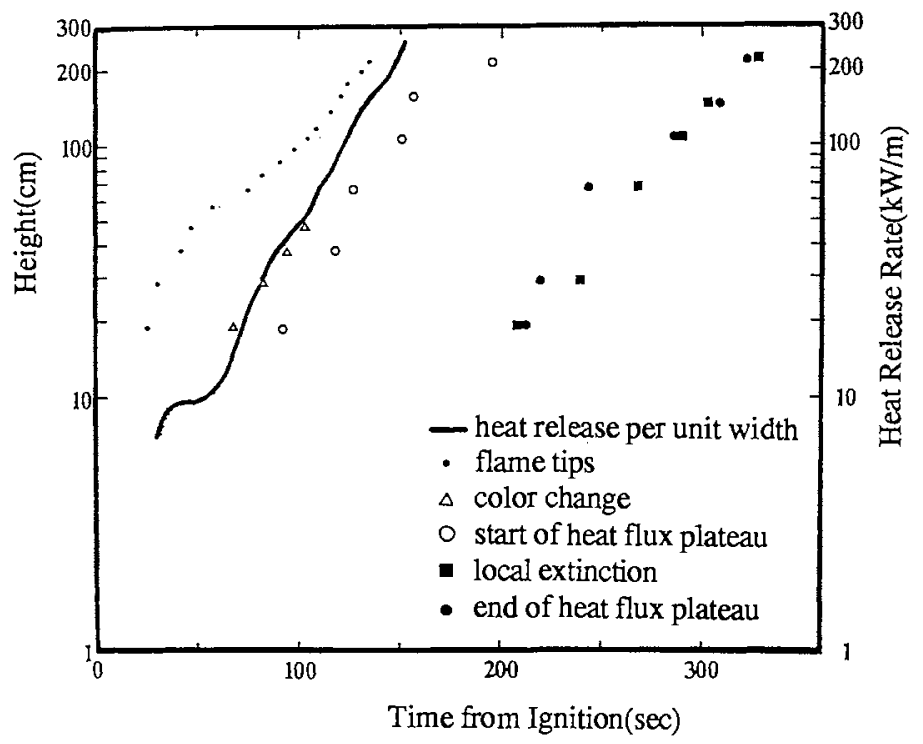

FIGURE 5 An Example Summary of Major Episodes during a Flame Spread Test $12.6 \mathrm{~mm}$ thick Douglas Fir Particleboard, $\mathrm{q}_{\mathrm{e}}=6.0 \mathrm{~kW} / \mathrm{m}^{2}, \mathrm{~T}_{\mathrm{si}}=157^{\circ} \mathrm{C}$ (Thermal Equilibrium)

as the specimen at its lower edge when the surface temperature of the specimen has reached a preset temperature by the external radiation, mostly the thermal equilibrium. Figure 3 shows the experimental set-up. Measurements were made on surface temperature, surface heat flux, heat release rate and its convective fraction. Backsurface temperatrure and mass loss rate were also measured at some of the tests. Visual observation was made on videotapes. Detailed description of the experiment is given elsewhere[10]. In the time history of surface heat flux, a clear plateau has been observed at most of the tests as seen in Figure 4. Temperature of the surface at the start of the heat flux plateau at that height for Douglas Fir Particleboard was within the range $340 \sim 400^{\circ} \mathrm{C}$, close to the igition temperature in literature[11]. Change of the surface color to dark brown has been observed prior to the start of the heat flux plateau. Surface temperature at the color change was around $260^{\circ} \mathrm{C}$, and is clearly lower than the ignition temperature. According to the visual observations, the surface was not covered with a stable flame until the heat flux plateau was established. From these observations, it is believed that the start of the heat flux plateau correspond with the arrival of the front of a zone feeding fuel directly to the flame, whereas pyrolysis itself is believed to start earlier. Since direct feeding of fuel to the wall flame is more essential for flame spread than the pyrolysis itself, the start of the heat-flux plateau will be referred to as $x_{p}$ in this paper. The end of the heat flux plateau corresponds nearly with the local extinction. Figure 5 is an example of the measurement result; interval between the arrivals of flametips and the pyrolysis front decreases with height at all tests, while equation(1) assumes a constant interval. The duration of the heat-flux plateau, 


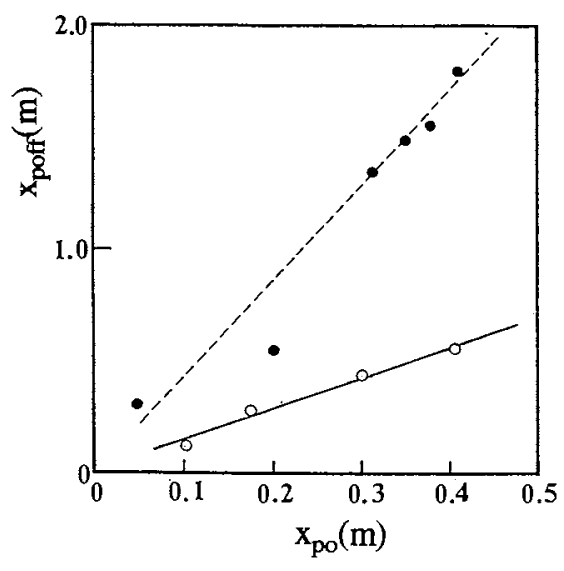

FIGURE 6 Relation between Pilot Flame Height, $x_{\text {po }}$, and Maximum Pyrolysis Front, $x_{\text {poff }}$ open: $10 \mathrm{~mm}$ thick Oak, no external radiation, solid: $12 \mathrm{~mm}$ thick Lauan Plywood, $\mathrm{q}_{\mathrm{e}}=4.0$ $\mathrm{kW} / \mathrm{m}^{2}, \mathrm{~T}_{\mathrm{si}}=120^{\circ} \mathrm{C}$ (Thermal Equilibrium)

supposed to be equivalent to $t_{b}$, is almost constant. At some tests with weak external radiation, $x_{p}$ or even $x_{f}$ did not reach the top of the specimen. Figure 6 shows examples of the relation between $x_{p o f f}$ and $x_{p o}$ for such experimental condition; as expected from the model in the previous section, $x_{\text {poff }}$ is practically proportional to $x_{p o}$.

\section{MATERIAL PROPERTIES UNDER SIMULATED SURFACE HEAT FLUX}

For the validation of the flame spread model, it is necessary to obtain such material properties as $\mathrm{a}$ (or $\mathrm{q}_{\mathrm{o}}$ ) and $\lambda$ (or $\mathrm{t}_{\mathrm{b}}$ for a rectangular heat release function). Measurement of these properties for different heating conditions is important also to see how flame spread is affected by fire conditions. Among these properties, $a\left(\right.$ or $\mathrm{q}_{\mathrm{o}}$ ) and $\lambda$ (or $\mathrm{t}_{\mathrm{b}}$ ) relate to the material heat release characteristics. Although it is desirable that these properites be obtained from bench-scale tests, it is not yet clear if present bench-scale tests can reproduce the time history of local surface heat flux during a flame spread test. In order to avoid this uncertainty, heat release of the materials used for the flame spread tests has been measured on medium-size $(530 \mathrm{~mm} \times 590 \mathrm{~mm})$ specimens using the experimental arrangement identical to the flame spread tests. Different levels of external radiation and initial surface temperatures were chosen. Each specimen was exposed to the radiant panel and was ignited with a line burner at the bottom of the specimen when the surface temperature has reached a preset temperature.Flame from the line burner gives around $20 \mathrm{~kW} / \mathrm{m}^{2}$ uniform heat flux to reproduce the pattern of the change of heat flux during a corresponding flame spread test. Heat release from the specimen was obtained from the difference between the measured heat release and the heat release from the burner measured with an inorganic board instead of a combustible specimen. Figure 7 shows relation between $q_{0}$ and level of external radiation, $q_{e}$, for various initial surface temperatures. $q_{o}$ increases clearly with $\mathrm{q}_{\mathrm{e}}$ until $\mathrm{q}_{\mathrm{e}} \doteqdot 10 \mathrm{~kW} / \mathrm{m}^{2}$ for the tested forest products. The decrease of $\mathrm{q}_{\mathrm{o}}$ for $\mathrm{q}_{\mathrm{e}}$ greater than this range is probably due to the dissipation of fuel prior to the ignition. Figure 8 shows 


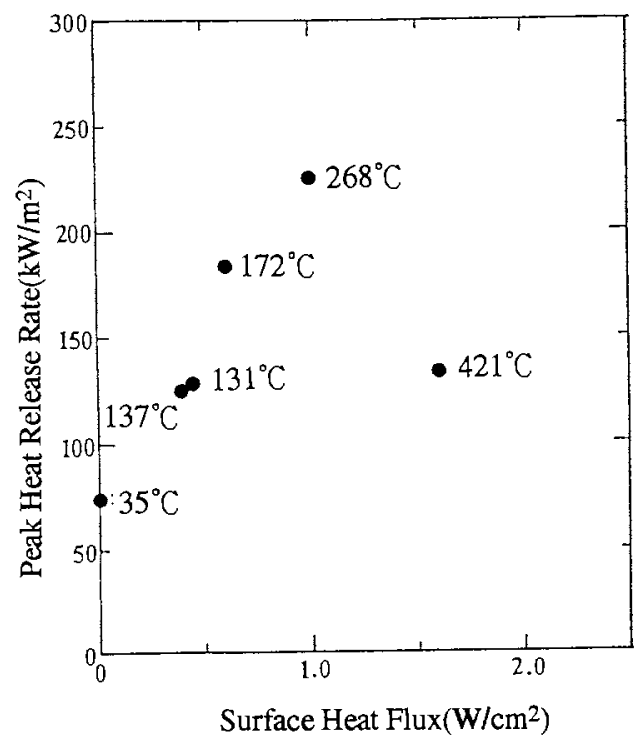

FIGURE 7 Relation between External Radiation and Peak Heat Release Rate Douglas Fir Particleboard(associated temperatures denote $\mathrm{T}_{\mathrm{si}}$ )

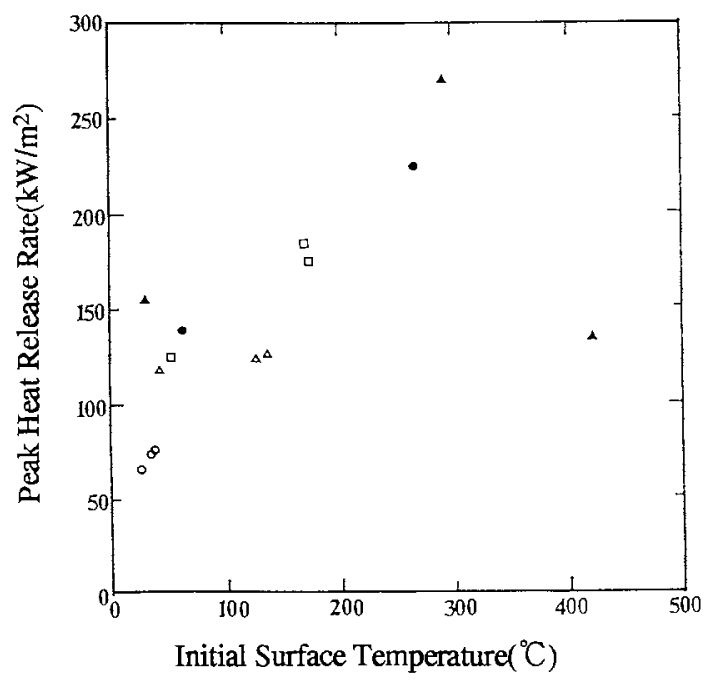

FIGURE 8 Relation between Initial Surface Temperature and Peak Heat Release Rate, Douglas Fir Particleboard $\left(O\right.$ :no external radiation, $\triangle: q_{\mathrm{e}}=4.0 \mathrm{~kW} / \mathrm{m}^{2}, \square: \mathrm{q}_{\mathrm{e}}=6.0 \mathrm{~kW} / \mathrm{m}^{2}$, $: \mathrm{q}_{\mathrm{e}}=10.0 \mathrm{~kW} / \mathrm{m}^{2}, A: \mathrm{q}_{\mathrm{e}}=16.0 \mathrm{~kW} / \mathrm{m}^{2}$ ) 


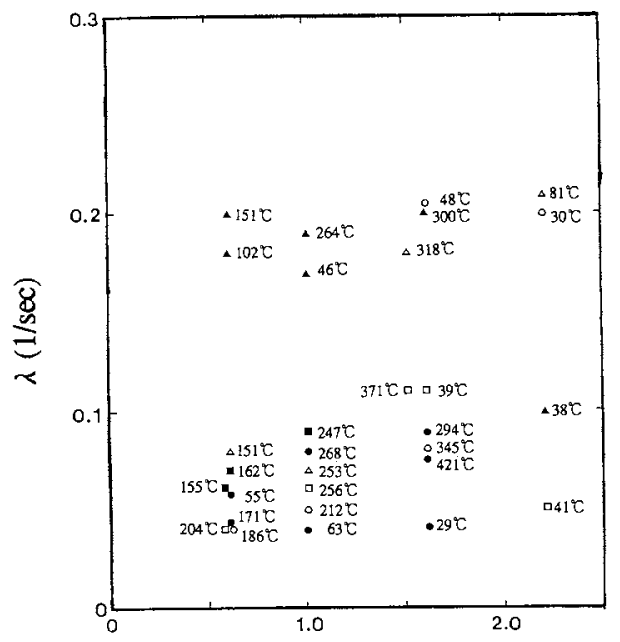

Surface Heat Flux $\left(\mathrm{W} / \mathrm{cm}^{2}\right)$

Figure 9 Relation between External Heat Flux and Heat Release Decay Coefficient, $\lambda$

(associated temperatures denote $\mathrm{T}_{\text {si. }} \quad \mathbf{O}$ :Particleboard 12.6mm thick, $\Delta$ :Plywood $12 \mathrm{~mm}$ thick, Z:Lauan Plywood 5.5mm thick, $\bigcirc:$ Lauan Plywood $9 \mathrm{~mm}$ thick, $\triangle$ :Lauan Plywood $12 \mathrm{~mm}$ thick, $\square:$ Lauan Plywood $18 \mathrm{~mm}$ thick)

correlation between $q_{o}$ and initial surface temperature, $T_{s i}$, for particleboard. Considerably lower $\mathrm{q}_{\mathrm{o}}$ for $\mathrm{T}_{\mathrm{si}} \doteqdot 400^{\circ} \mathrm{C}$ than for lower $\mathrm{T}_{\mathrm{si}}$ is again attributed to the pre-ignition loss of fuel. These demonstrate significance of the influence of external radiation on upward flame spread over a charring combustible wall. However, such clear dependence on heating conditions was not seen for $\lambda$ nor $t_{b}$ (e.g.,Figure 9).

$\tau$ is expected to be a function of ignitability and preheat conditions. While previous analyses based on the linearized flame length approximation commonly assume uniform preheating of the unburnt surface covered by a wall flame[4,6,7], upward flame spread tests demonstrate notable transiency in the preheating by the visible flame(Figure 4) which has been found to be consistent with the wall flame heat transfer correlation for steady wall fires [2,12].Also it is important that $\tau$ is not equivalent to the interval between the arrivals of flame front and pyrolysis front observed during a flame spread test, $t^{*}$. This discrepancy can be easily demonstrated using the solution of equation(1) for $q(t)=q_{0}$ with the pilot flame off after $t=0$ for $\mathrm{x}_{\mathrm{p}}, \mathrm{x}_{\mathrm{p}}=\mathrm{x}_{\mathrm{po}} \exp \{(\mathrm{a}-1) \mathrm{U} \tau\}$, and the relation $\mathrm{x}_{\mathrm{f}}(\mathrm{t})=\mathrm{ax}_{\mathrm{p}}(\mathrm{t})=\mathrm{x}_{\mathrm{p}}\left(\mathrm{t}+\mathrm{t}^{*}\right)$; the flame-front-to-pyrolysisfront time for this particular mode can be obtained as $t^{*}=\tau \ln (a) /(a-1)$. For $a>1, t^{*}$ is always shorter than $\tau$, while for $\mathrm{a}<1 \mathrm{t}^{*}$ is longer. Relation between $\tau$ and $\mathrm{t}^{*}$ for more complicated $\mathrm{q}(\mathrm{t})$ forms should be harder to formulate. One practical approach to avoid ambiguity occurring from this discrepancy and to incorporate the transiency in the preheating by wall flame in the 
evaluation of $\tau$ is the use of a theoretical $\Psi=\pi \mathrm{k} \rho \mathrm{c}\left(\mathrm{T}_{\mathrm{ig}}-\mathrm{T}_{\mathrm{si}}\right)^{2} \mathrm{~V}_{\mathrm{p}} / \mathrm{x}_{\mathrm{p}}$ vs $\mathrm{Q}_{\ell}{ }^{*}$ diagram[13], which was originally derived for steady local heat release. $\tau$ can be then estimated from $\tau=\pi$ $\mathrm{k} \rho \mathrm{c}\left(\mathrm{T}_{\mathrm{ig}}-\mathrm{T}_{\mathrm{si}}\right)^{2}\left(\mathrm{x}_{\mathrm{f}} / \mathrm{x}_{\mathrm{p}}-1\right) / \Psi$ where $\mathrm{k} \rho \mathrm{c}\left(\mathrm{T}_{\mathrm{ig}}-\mathrm{T}_{\mathrm{si}}\right)^{2}$ can be estimated from the ISO5657 ignitability test with $\mathrm{T}_{\mathrm{ig}}$ in literature or measured during an ignitability test. Evaluation of $\tau$ by this approach essentially needs an iteration for obtaining $\tau$ and $Q_{\ell}{ }^{*}$ simultaneously from equation(1) and the $Q_{\ell}{ }^{*} \Psi$ diagram, since $Q_{\ell}{ }^{*}$ is dependent on $V_{p}$, which is further a function of $\tau . \mathrm{x}_{\mathrm{f}} / \mathrm{x}_{\mathrm{p}}$ can be estimated from flame height correlation, e.g. $\mathrm{x}_{\mathrm{f}}=6.0 \mathrm{Q}_{\ell}{ }^{2 / 3} \mathrm{x}_{\mathrm{p}}[2]$.

\section{COMPARISON BETWEEN THEORY AND EXPERIMENTS}

Validation of the theoretical framework for upward flame spread was made by comparing measured $x_{\text {poff }} / x_{p o}$ with calculation using experimental material properties. Conditions of the flame spread tests are superimposed on Figure 1(a) and Figure 2. The number associated with each solid symbol is the measured $x_{\text {pof }} d x_{\text {po }}$ value for that condition. $q_{o}, \lambda$ and $t_{b}$ were evaluated by approximating the material heat release rate by an exponential or rectangular function. Data for q(t) showing exponential decay are used in Figure 1(a), and those closer to a rectangular function are plotted on Figure 2. Open symbols represent tests in which flame spread reached the top of the specimen, i.e. $x_{p o f f} / x_{p o}>50$. The calculation is not far from the tests; however the agreement may still be critical. This uncertainty should be partly attributed to the extreme sensitivity of $x_{\text {poff }} / x_{\text {po }}$ in the large $x_{\text {poff }} / x_{\text {po }}$ domain. $K=0.018$ was taken from experimental correlation between heat release rate and flame length.In the calculation of $\tau, \Psi$ was evaluated from the "steady mode" of the $\Psi-\mathrm{Q}_{\ell}{ }^{*}$ diagram using $\mathrm{Q}_{\ell}$ * determined such that the excess wall heat flux above $q_{e}$ in each flame spread test can trace the wall-heat-transfer vs $\mathrm{Q}_{\ell}{ }^{* 2 / 3} \mathrm{x}_{\mathrm{p}}$ relation for steady wall fires [2]. It is important to note that the present calculation is not a prediction but validation of the model framework by experiment in the sense that $Q_{\ell}{ }^{*}$ and $\mathrm{x}_{\mathrm{f}} / \mathrm{x}_{\mathrm{p}}$ were evaluated using the flame spread tests. Ignition temperature in literature was used for $\mathrm{T}_{\mathrm{ig}}$, i.e. $382^{\circ} \mathrm{C}$ for particleboard[11] and $390^{\circ} \mathrm{C}$ for lauan plywood[11,14]. Direct substitution of $t^{*}$ into $\tau$ has always resulted in notable overestimate of $x_{p o f} / x_{p o}$ for the present test conditions. Assumption of uniform heat flux between $x_{p}$ and $x_{f}$ also has resulted in considerable overestimate of $x_{p o f f} / x_{p o}$ as long as the usual value, $20-30 \mathrm{~kW} / \mathrm{m}^{2}$, is assumed for wall-flame heat transfer.

\section{CONCLUDING REMARKS}

Result of the present work seems to demonstrate a good prospect of an engineering evaluation on upward flame spread along a combustible wall being established on the basis of the linearized flame spread theory. Especially both the tests and the theory suggest that $x_{\text {poff }} f x_{p o}$ can be a practical measure to evaluate fire safety related to this process. A large $x_{\text {poff }} / x_{\text {po }}$ value 
suggests not only high fire hazard but also low reliability of the achieved safety. However, careful interpretation should be necessary in the comparison between the theory and tests. Necessity of further research should be emphasized on the establishment of correlation between local heat release during a full-scale wall fire and bench-scale tests.

\section{ACKNOWLEDGEMENTS}

The experiments were started as an U.S.-Japan cooperative programme. The authors are grateful to Dr.J.G.Quintiere for his contribution to the initiation of the programme. The authors also wish to thank Messrs. T.Nakabayashi, S.Takashima and R.Kikuchi, graduate students of Science University of Tokyo, for assistance in the experiments, and Drs. T.Kashiwagi, M.A.Delichatsios, A.Kulkarni and B.Karlsson for useful discussions.

\section{REFERENCES}

1.Saito,K., Quintiere,J.G., and Williams,F.A.:"Upward Turbulent Flame Spread", Proc., First International Symposium on Fire Safety Science, Gaithersburg, Md., 1985.

2.Hasemi,Y.:"Thermal Modeling of Upward Flame Spread", Proc., First International Symposium on Fire Safety Science, Gaithersburg, Md., 1985.

3.Mitler,H.:"Predicting the Spread Rates of Fires on Vertical Surfaces", Proc., 23rd (International) Symposium on Combustion, 1990.

4.Thomas,P.H., and Karlsson,B,:"On Upward Flame Spread", Department of Fire Safety Engineering, Lund University, 1991.

5.Delichatsios,M.M., Mathews,M.K., and Delichatsios,M.A.:"An Upward Fire Spread and Growth Simulation", Proc., Third International Symposium on Fire Safety Science, Edinburgh, 1991.

6.Mowrer,F.W., and Williamson,R.B.:"Flame Spread Evaluation for Thin Interior Finish Materials", Proc., Third International Symposium on Fire Safety Science, Edinburgh, 1991.

7.Baroudi,D., and Kokkala,M.:"Analysis of Upward Flame Spread", VTT Publications 89, 1992.

8.Brehob,E.G., and Kulkarni,A.K.:"A Numerical Model for Upward Flame Spread under External Radiation", Annual Conference on Fire Research, Rockville, MD., 1993.

9.Hasemi,Y., and Yasui,N.:"A Strategy to Develop Engineering Upward Flame Spread Evaluation Based on the Linearized Flame Height Approximation", submitted to Fire Science and Technology.

10.Hasemi,Y., Yoshida,M., and Yasui,N.:"Upward Flame Spread along Vertical Charring Materials", Proc., First Japan Symposium on Heat Release and Fire Hazard, Tsukuba, 1993.

11.DiNenno,P.J., Ed-Chief :"The SFPE Handbook of Fire Protection Engineering", SFPE,NFPA, 1988.

12.Quintiere,J.G., Harkleroad,M., and Hasemi,Y.:"Wall Flames and Implications for Upward Flame Spread", Combustion Science and Technology, Vol.48, 1986.

13.Hasemi,Y., Yoshida,M., Nohara,A., and Nakabayashi,T.:"Unsteady-State Upward Flame Spreading Velocity along Vertical Combustible Solid and Influence of External Radiation on the Flame Spread", Proc., Third International Symposium on Fire Safety Science, Edinburgh, 1991.

14.Japan Association for Fire Science and Engineering:"Kaitei Kasai Binran(Fire Handbook, Revised Version) ${ }^{n}$, Kyoritsu Publishers, 1984(in Japanese). 